УДК 663,697,667.6

DOI

\title{
ІННОВАЦІЙНІ СОНЯЧНІ СУШАРКИ НА ОСНОВІ СОНЯЧНИХ ТЕПЛОВИХ ПОВІТРЯНИХ КОЛЕКТОРІВ
}

Мусій Р.Й., канд. хім. наук., ст. наук. співр. ${ }^{1}$, Заборовський А.Б. ${ }^{1}$, мол. наук. співр.,

Гальчак В.П. ${ }^{2}$, канд. фіз. -мат. наук, доцент, Желєзко О. П. ${ }^{3}$, інженер-конструктор

${ }^{1}$ Відділення фізико-хімії горючих копалин Інституту фізико-органічної хімії і вуглехімії

ім. Л. М. Литвиненка Національної академії наук України, м. Львів

2 Львівський національний аграрний університет, м.Львів-Дубляни,

${ }^{3}$ Національний технічний університет України «Київський політехнічний інститут», Міжгалузевий НДІ "РИТМ", м.Київ

\begin{abstract}
Анотація
Нами розроблені спеціально сконструйовані сушарки, які працюють виключно на сонячній енергії. Застосовуються для сушіння різних продуктів харчування - фруктів, овочів, лікарських трав, ягід, грибів $i$ т.д. При цььому використовуються сонячні теплові повітряні колектори (СТПК), які виготовлені нами на основі розробленого нами селективного покриття. Дослідження теплотехнічних характеристик СТПК проводили на спеціально сконструйованому експериментальному стенді. $B$ результаті випробувань підтверджено, ш⿻ вентилятори системи можуть підтримувати подачу повітря в межах 20-120 $\mathrm{m}^{3} / 20$. Влітку, при температурі $25-35^{\circ} \mathrm{C}$, температура потоку повітря на виході з колектора може досягати 70 $75{ }^{\circ} \mathrm{C}$. Для иілодобової сушки передбачені інноваційні акумулятори енергії, розроблені в Національному технічному університеті Украӥни «Київський політехнічний інститут». В даний час для таких типів сонячних сушарок нами розроблясться система контролю та регулювання температури $і$ вологості сушіння, шьо дуже важливо при сушінні лікарських трав, зернових культур, грибів.
\end{abstract}

Ключові слова: сонячний тепловий повітряний колектор, експериментальний випробувальний стенд, акумулятор, цілодобове сушіння

\section{INNOVATIVE SOLAR DRYER BASED ON SOLAR THERMAL AIR COLLECTORS}

Musiy R.Y., Zaborovskiy A.B.

Department of Physical Chemistry of Fossil Fuels of the Institute of Physical-Organic Chemistry and Coal Chemistry named after L. M. Lytvynenko of the National Academy of Sciences of Ukraine, Lviv, Ukraine

Halchak V.P.

Lviv National Agricultural University, Lviv-Dublyany, Ukraine

Zheliezko O. P.

National Technical University of Ukraine "Kyiv Polytechnic Institute" Interdistrict Research Institute "RYTM", Kyiv, Ukraine

Abstract. Currently, alternative energy sources are very important for preservation of the environment. In the food industry one of the most common types of storage products is the drying. When using gas and electricity, this process becomes very expensive. We have designed specially driers that work exclusively on solar energy. They used for drying various foods - fruits, vegetables, herbs, berries, mushrooms, etc. For the drying process are used solar thermal air collectors (STAC) which made by us on the basis of our selective absorbent coating. The research of the thermal characteristics of the STAC was carried out on a specially constructed experimental stand. As a result of the tests it was confirmed that the fans of the system can support air supply in the range of $20-120 \mathrm{~m}^{3} / \mathrm{h}$. In the summer, at a temperature of $25-35^{\circ} \mathrm{C}$, the temperature of the flow of air at the outlet from the collector can reach 70 $75^{\circ} \mathrm{C}$.

For all-time drying there are developed special innovative energy storage batteries at National Technical University of Ukraine "Kyiv Polytechnic Institute". Batteries can be charged from solar panels, have a shorter charging time, the possibility of charge-discharge at low and high temperatures, higher reliability, are safe and durable.

At present, for such types of solar dryers we are developing special devices for controlling and regulating the temperature and humidity of drying, which is very important when drying medicinal herbs, cereals, fruits, mushrooms, etc. Indeed, the deviation of a few degrees during the drying of such products can significantly change their consumer characteristics. 
Our innovative and efficient solar dryers systems provide a very easy installation, with the ability to fit in the garden, on any area or indoors. In this case, a person does not bear any costs and additional charges for maintenance during their operation, as they fully work from the energy of the sun.

Keywords: solar thermal air collector, experimental test bench, accumulator, all-days drying.

Вступ. Основним завданням для виробників в харчовій галузі є максимальне збереження корисних властивостей сільськогосподарської продукції при доведенні ії до споживача. $€$ різні способи зберігання продуктів і консервації їх поживних властивостей: - фрукто- та овочесховища, - термічна обробка високими температурами; - замороження в морозильних камерах; - насичення продуктів консервантами; - вакуумування, бродіння, обезводнення та інші. Всі вони потребують дорогого обладнання та великих енергозатрат.

Аналіз проблематики та рішення. Одним з найбільш розповсюджених способів $є$ сушіння. Це простий i зручний, перевірений тисячоліттями, спосіб концентрації і тривалого зберігання всіх корисних і лікувальних властивостей фруктів, овочів, лікувальних трав, ягід, грибів, риби. При цьому у висушених продуктах зберігаються вітаміни, колір, смак, запах [1-4].

Хоча сушіння є високорозвиненою технологією, цей процес теж вимагає великого споживання енергії $[5,6]$. Для його зменшення необхідно вибрати ефективну систему сушіння. В даний час для збереження навколишнього середовища дуже важливо використовувати альтернативні джерела енергії. Саме 3 цієї причини в останні роки збільшився інтерес до використання сонячних сушарок [7-8]. Сонячна енергія є невичерпною, ефективною, безпечною для оточуючого середовища, не дає викидів вуглекислого газу в атмосферу та поки що безкоштовною.

3 цією метою нами сконструйовані сонячні сушарки, які працюють на сонячній енергії (Рис. 1). Як видно з Рис. 1, сонячні сушарки складаються з сушильної камери та сонячного теплового повітряного колектора. Для процесу сушки використовуються СТПК. Такі колектори працюють виключно на енергії сонця, продуваючи через сушильну камеру екологічно чисте тепле повітря, не забруднюючи при цьому продукти та навколишне середовище. Сушильні камери виготовляються з спеціальних сортів дерева, які не дають запахів.
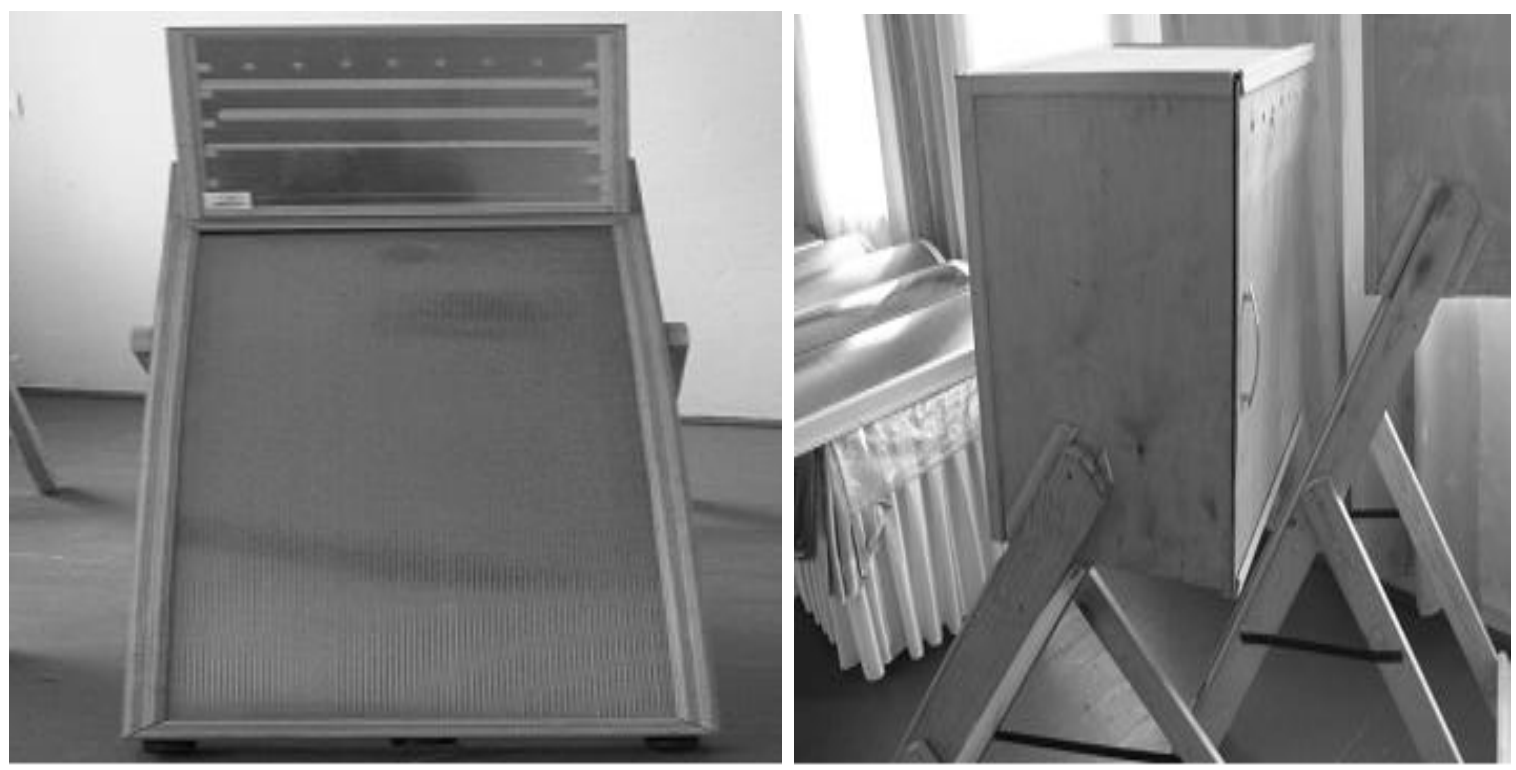

Рис. 1. Сонячна сушарка: вид спереду та вид збоку.

Сонячні колектори виготовляються нами на основі нашого селективного покриття (Рис.2) [9]. В їх комплект входять: - сприймаюча панель з селективним покриттям, яка перетворює сонячну енергію в теплову; сонячний фотоелектричний модуль для генерування необхідної напруги, яка використовується для роботи вентиляторів системи подачі повітря, електронного модуля контролю температури і вологості, зарядки акумуляторів.

Традиційно сонячну енергію використовують з метою гарячого водопостачання за допомогою водяних колекторів промислового виробництва з експериментально встановленими технічними характеристиками та генерування електричної енергії. Натомість український ринок сонячних повітряних колекторів практично 
відсутній, а їхні технічні характеристики відомі тільки наближено. В Україні повітряні колектори для сонячних сушарок, теплиць, систем енергоощадної вентиляції приміщень тощо, виготовляють окремі ентузіасти, зусиллями яких виготовлено одиничні зразки та оцінено окремі параметри $[10,11]$. Тому потреба у розробці обладнання для випробування і сертифікації сонячних повітряних колекторів залишається актуальною.

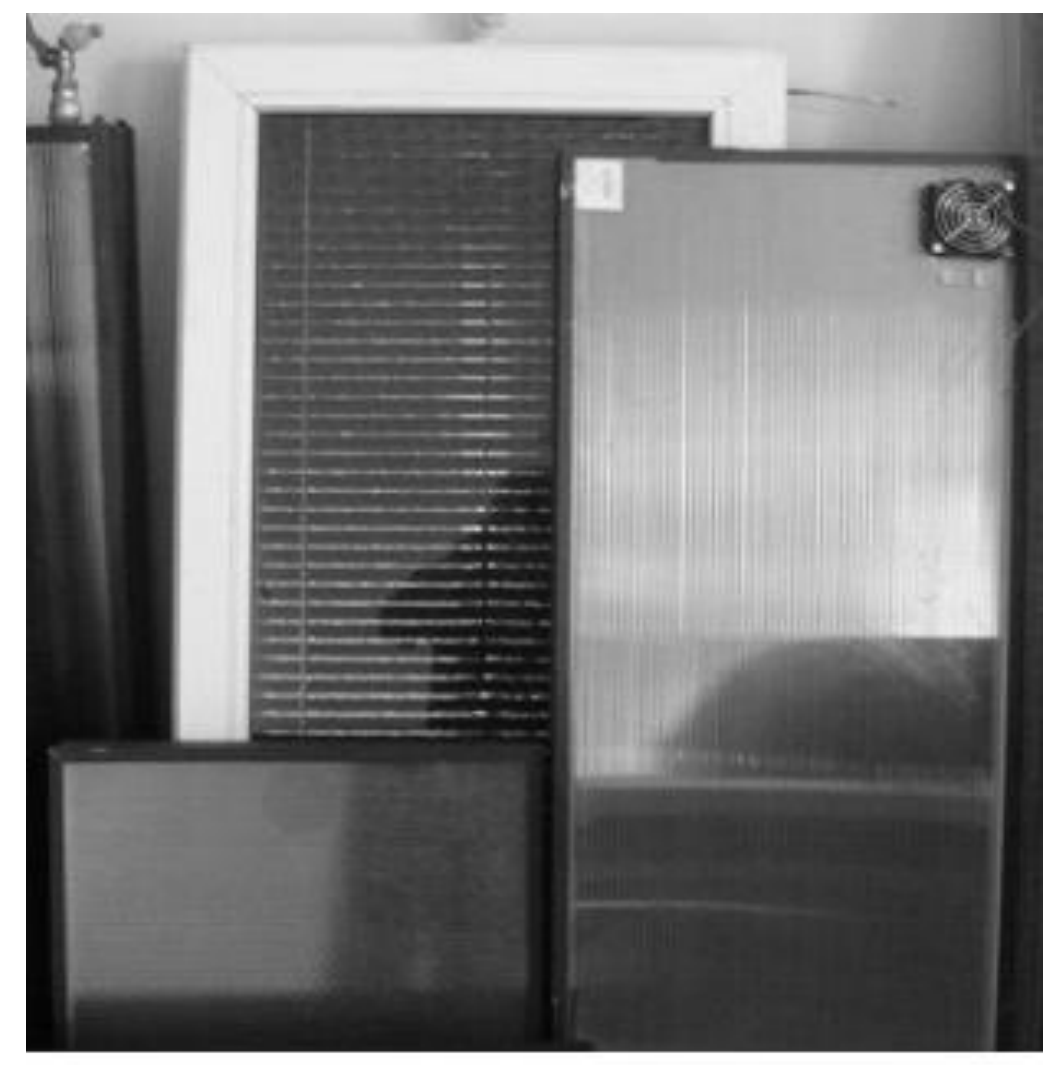

\section{Рис.2. Сонячні теплові повітряні колектори різних конструкцій}

\section{Матеріали та методи досліджень}

Нами розроблені СТПК різних конструкцій і модифікацій. Загальна теорія сонячного колектора наведена у монографії [12], а літературний огляд методів їх випробування у роботі [13]. Згідно з ними ефективність сонячного колектора одиничної площі у широкому інтервалі зміни вхідних та вихідних параметрів повністю описується рівнянням для коефіцієнта корисної дії (к.к.д.):

$$
\eta=F^{\prime}\left(\tau \alpha-U_{L} \frac{\bar{t}-t_{H c}}{E}\right),
$$

де: $\bar{t}=\left(t_{\text {sx }}+t_{\text {виx }}\right) / 2$ - середня температура на вході і виході колектора; $F^{\prime}$ - коефіцієнт тепловідводу світлопоглинаючої панелі; $\tau \cdot \alpha$ - оптичний к.к.д. колектора, рівний добутку пропускання світлопрозорого покриття $\tau$ i коефіцієнта поглинання $\alpha$ покриття сприймаючої панелі; $U_{L}-$ повний коефіцієнт тепловтрат колектора; $E$ - енергетична освітленість сприймаючої поверхні.

Чисельні значення коефіцієнтів $F^{\prime}(\tau \alpha)$ та $F^{\prime} U_{L}$ визначають у результаті випробувань, умови і порядок яких регламентуються державними стандартами $[4,5]$. Зокрема добуток $F^{\prime} U_{L}$ визначають при темнових випробуваннях, пропускаючи через колектор гарячий теплоносій - у випадку повітряного колектора - повітря. Результат розраховують за формулою:

$$
F^{\prime} U_{L}=\frac{G_{n u m} \cdot c_{p}\left(t_{B x}-t_{\text {sux }}\right)}{\left(\bar{t}-t_{\mu c}\right)}
$$


де $G_{\text {пит }}$ - питома (на одиницю площі поверхні) витрата повітря у кг $/ \mathrm{c} \cdot \mathrm{M}^{2} ; c_{p}-$ питома теплоємність повітря Дж/кг К К;

Натомість добуток $F^{\prime}(\tau \alpha)$ визначають графічною екстраполяцією до нуля функціональної залежності поточного к.к.д. (визначеного через відношення теплопродуктивності до енергетичної освітленості $\eta=Q_{u} / E$ ) від комплексу

$$
\eta=\frac{Q_{u}}{E}=\frac{G_{\text {num }} c_{p}\left(t_{\text {виx }}-t_{\text {вx }}\right)}{E}=f\left(\frac{\bar{t}-t_{\text {нс }}}{E}\right)=f(t *)
$$

Але у випадку повітряних колекторів, у яких температура теплоносія на вході, як правило, рівна температурі навколишнього середовища, добуток $F^{\prime}(\tau \alpha)$ можна визначити безпосередньо, використовуючи співвідношення, запропоноване у публікації [6]:

$$
F^{\prime}(\tau \cdot \alpha)=\frac{F^{\prime} U_{L}\left(t_{\text {вих }}-t_{b x}\right)}{E\left[1-\exp \left(\frac{F^{\prime} U_{L}}{G_{\text {пит }} c_{p}}\right)\right]}
$$

Витрата теплоносія входить у показник експоненти, що вимагає особливої уваги до точності вимірювання швидкості потоку, співмірного зі швидкістю вітру. Тому випробування повітряних колекторів доцільніше проводити на спеціальних стендах у закритих приміщеннях з використанням природного або штучного освітлення.

Результати досліджень. Експериментальні дослідження теплотехнічних характеристик СТПК проводили на спеціально сконструйованому експериментальному стенді (Рис. 3.).

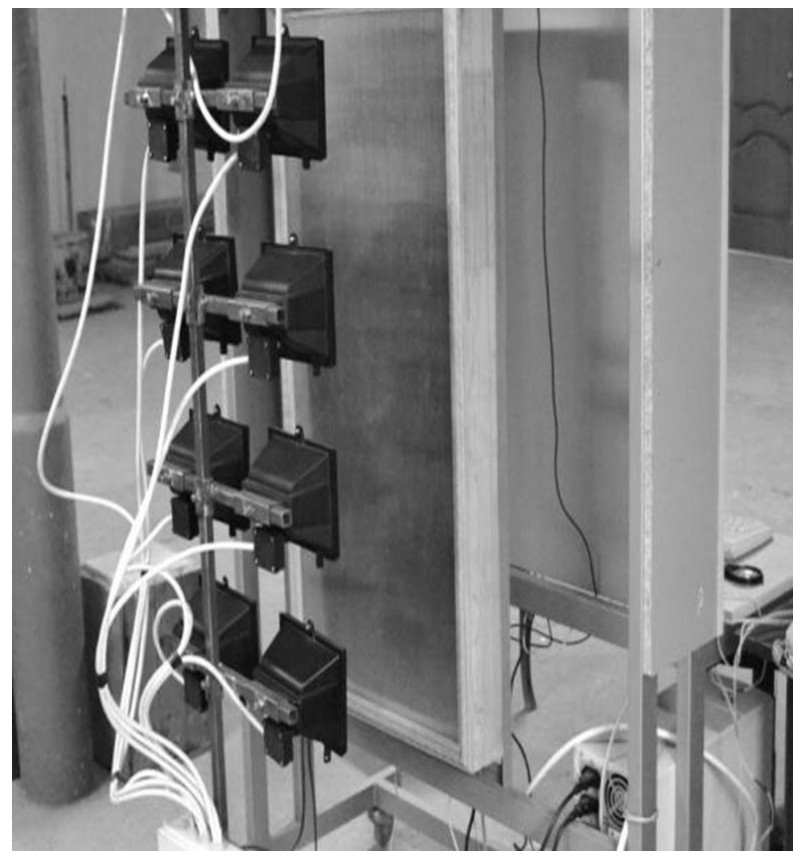

Рис. 3. Вигляд експериментального стенда для дослідження теплотехнічних характеристик СТПК

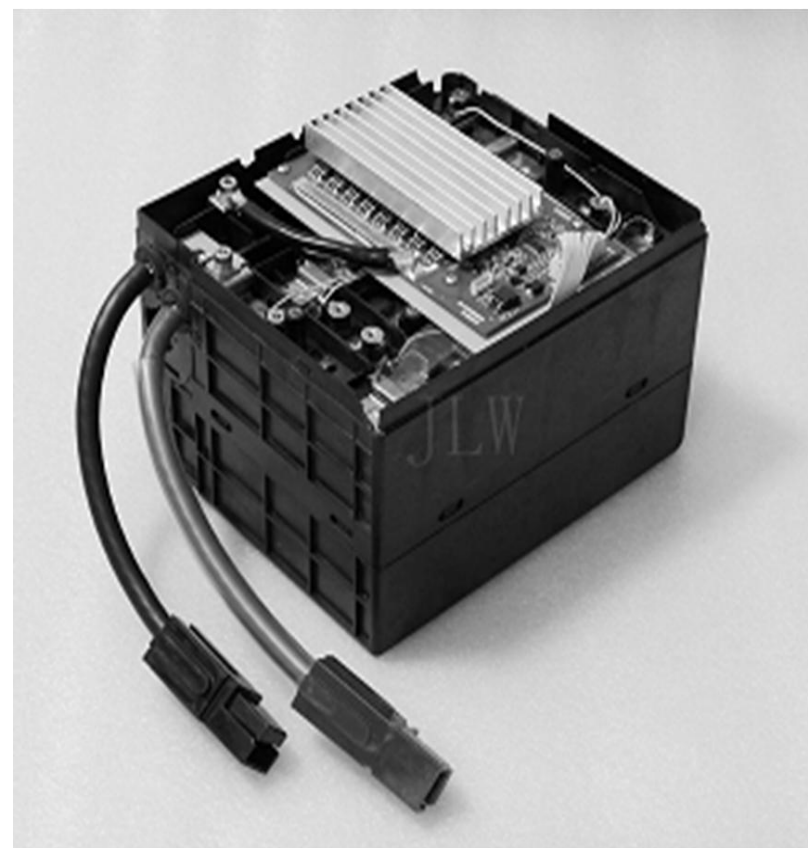

Рис. 4. Система накопичення і зберігання електричної енергії

Досліджувались СТПК різноманітних конструкцій, з різними моделями сприймаючих панелей колекторів та типами вентиляторів. В результаті випробувань підтверджено, що вентилятори системи підтримують подачу повітря в межах 20-120 м³/год. Літом, при температурі оточуючого середовища $25-35^{0} \mathrm{C}$ температура потоку повітря на виході з колектора може досягати $70-75^{\circ} \mathrm{C}$. Цього достатньо для проведення сушіння різних продуктів харчування - ягодів, фруктів, лікарських трав, грибів і т.д. 
Обговорення результатів. Для цілодобової сушки передбачені системи накопичення і зберігання електричної енергії, розроблені в НТУ України «Київський політехнічний інститут» НДІ "РИТМ" (Рис. 4.). Вони складаються з зарядної станції і нового типу акумуляторних батарей.

Акумулятори можуть заряджатися від сонячних панелей, мають менший час зарядки, можливість заряду-розряду при низьких і високих температурах, більш високу надійність, є безпечними і довговічнішими у порівнянні з існуючими моделями. Ці можливості дозволяють використовувати їх в якості високоефективного накопичувача енергії в стаціонарних системах акумулювання енергії.

В даний час для таких типів сонячних сушарок нами розробляються спеціальні пристрої для контролю та регулювання температури і вологості сушіння продуктів харчування, що дуже важливо при сушінні лікарських трав, зернових культур, фруктів, грибів і т.д. [14-15] Адже відхилення на кілька градусів при сушінні таких продуктів може суттєво змінити їхні поживні характеристики.

\section{Висновки}

Наші інноваційні та ефективні сонячні сушарки передбачають дуже просту установку, мають можливість розміщення в саді, городі, на будь якій місцевості чи у приміщеннях та дозволяють проводити цілодобове сушіння. При цьому людина не несе ніяких витрат і додаткових платежів на обслуговування під час їх експлуатації, так як вони повністю працюють від енергії сонця. Це є дуже зручно та економічно вигідно, тому що не вимагає практично присутності людини під час їх роботи.

\section{Reference}

1. Akyol, E., Susantez, C., Kahveci, K., Hacihafizoglu, O., Kaya, Y. (2015), Drying Simulation of Pumpkin Seed, Proceedings of the World Congress on Mechanical, Chemical, and Material Engineering (MCM 2015) Barcelona, Spain - July 20-21, Paper No. 320.

2. Hashim, N., Daniel, O., Rahaman, E. (2014), A Preliminary Study: Kinetic Model Of Drying Process Of Pumpkins (Cucurbita Moschata) İn A Convective Hot Air Dryer, Agriculture and Agricultural Science Procedia, 2, pp. 345-352.

3. Pazyuk, V., Petrova, Z., \& Chepeliuk, O. (2018). Determination of rational modes of pumpkin seeds drying. Ukrainian Food Journal, 7(1).

4. Matkivska, I., Atamanyuk, V., Symak, D. (2014) Basic regularities of the filtration drying of wheat grain. East European Journal of Enterprice Technology,. 5 (5). 14 - 18.

5. Caputo, A.C., Scacchia, F., Pelagagge, P.M. (2003) Disposal of by-products in olive oil industry: wastetoenergy solutions. Appl. Therm. Engg. 23(2), 197-214.

6. Markowski, M., Sobieski, W., Konopka, I., Tańska, M., Białobrzewski, I. (2007). Drying characteristics of barley grain dried in a spouted-bed and combined IR-convection dryers. Drying Technology, 25(10), 1621 1632.

7. Smitabhindu, R., Janjai, S., Chankong, V. (2008) Optimization of a solar-assisted drying system for drying bananas. Renew. Energy. 33, 1523-1531.

8. Barnwal, P., Tiwari, G.N. (2008) Grape drying using hybrid photovoltaic thermal (PV/T) greenhouse dryer: an experimental study. Solar Energy. 82, 1131-1144.

9. Musiy, R., Midyana, G., Makitra, R., Vasyutin, Y., Hovanets, G.I., Zaborovskiy, A. (2014) Sonyachnuy teplovuj kolektor na osnovi novogo tupy selectuvnogo pokruttya. Nauka ta innovacii, 10(1), 24-31.

10. Dudikevich, Yu.B. (2018) Sitchasti sonyachni povitryani kolektoru svoimu rykamu. Retrieved from: http://www.budexpert.ua/content/detail/314.

11. Sonyachni povitryani kolektoru. Konstrykciya i zastosyvannya. Retrieved from: http://chandelle.com.ua/18.54.0.0.1.0.phtml.

12. Duffy, J., Beckmann, U.A. (1987) Teplovue processu s ispolzovaniem solnechnoy energii. 420 p.

13. Fried, S.E. (1988) Metodu teplovuh isputaniy solnechnuh kollektorov. Prepress IVTAN 3-248. 56 p.

14. Soares, M. A. B., Jorge, L. M. M., Montanuc, F. D.(2016) Drying kinetics of barley grains and effects on the germination index //Food Science and Technology, 36(4). 638-645.

15. Mykhailyk, V., Lementar, S., Yakobchuk, R., Skrynnyk, Y., Semenko, R. (2016) Wheat grain drying kinetics in a thin layer, Ukrainian Journal of Food Science, 4(2), 316-326.

Отримано в редакцію 05.05.2019

Прийнято до друку 22.06.2019
Received 05.05.2019

Approved 22.06.2019 